\title{
UVC Irradiation for Pathogen Reduction of Platelet Concentrates and Plasma
}

\author{
Axel Seltsam Thomas H. Müller \\ German Red Cross Blood Service NSTOB, Institute Springe, Germany
}

\author{
Keywords \\ Pathogen inactivation - UVC . Platelet concentrates · \\ Plasma Blood units
}

\section{Summary}

Besides the current efforts devoted to microbial risk reduction, pathogen inactivation technologies promise reduction of the residual risk of known and emerging infectious agents. A novel pathogen reduction process for platelets, the THERAFLEX UV-Platelets system, has been developed and is under clinical evaluation for its efficacy and safety. In addition, proof of principle has been shown for UVC treatment of plasma units. The pathogen reduction process is based on application of UVC light of a specific wavelength ( $254 \mathrm{~nm}$ ) combined with intense agitation of the blood units to ensure a uniform treatment of all blood compartments. Due to the different absorption characteristics of nucleic acids and proteins, UVC irradiation mainly affects the nucleic acid of pathogens and leukocytes while proteins are largely preserved. UVC treatment significantly reduces the infectivity of platelet units contaminated by disease-causing viruses and bacteria. In addition, it inactivates residual white blood cells in the blood components while preserving platelet function and coagulation factors. Since no photoactive compound needs to be added to the blood units, photoreagent-related adverse events are excluded. Because of its simple and rapid procedure without the need to change the established blood component preparation procedures, UVC-based pathogen inactivation could easily be implemented in existing blood banking procedures.

\section{Schlüsselwörter}

Pathogeninaktivierung - UVC . Thrombozytenkonzentrate · Plasma B Blutprodukte

\section{Zusammenfassung}

Obwohl die Infektionssicherheit in der Transfusionsmedizin einen sehr hohen Standard erreicht hat, bilden bekannte Erreger, die in den Screening-Tests nicht erfasst werden, sowie unbekannte Erreger eine Sicherheitslücke, die durch die Pathogenreduktion von Blutprodukten geschlossen werden könnte. Die THERAFLEX-UV-PlateletsTechnologie stellt ein neu entwickeltes Verfahren zur Pathogenreduktion von Thrombozytenkonzentraten dar. Es gibt bereits auch erste Ansätze zur UVC-Behandlung von therapeutischem Plasma. Das Verfahren basiert auf der Applikation von kurzwelligem ultraviolettem Licht (UVC) einer bestimmten Wellenlänge (254 nm). Erfolgskritisch ist eine gleichförmige Behandlung aller Blutbestandteile innerhalb eines Beutels. Sie wird dadurch erreicht, dass die Blutbeutel während des Bestrahlungsvorganges für eine optimale Durchmischung stark geschüttelt werden und dabei die Schichtdicke zeitlich und räumlich variiert. Über eine UVC-vermittelte kovalente Vernetzung von Nukleotiden in den Nukleinsäuren kommt es zu einem Verlust der Replikationsfähigkeit von Pathogenen und kernhaltigen Blutzellen. Aufgrund der unterschiedlichen Absorptionsmaxima von Nukleinsäuren und Proteinen werden gezielt nur die Nukleinsäuren degradiert, so dass Viren und Bakterien und auch Leukozyten inaktiviert werden, während die Funktion der Thrombozyten und die Gerinnungsfaktoren erhalten bleiben. Da für die Pathogen reduzierende Wirkung von UVC keine photoaktiven Substanzen benötigt werden, sind Nebenwirkungen durch Photoprodukte ausgeschlossen. Aufgrund seiner Einfachheit und schnellen Durchführbarkeit lässt sich das UVC-Pathogenreduktionsverfahren leicht in die bestehenden Herstellungsprozesse einer Blutbank integrieren.

\begin{tabular}{ll}
\hline KARGER & $\oplus$ 2011 S. Karger GmbH, Freiburg \\
Fax +497614520714 & Accessible online at: \\
Information@Karger.de & www.karger.com/tmh \\
www.karger.com &
\end{tabular}

Prof. Dr. med. Axel Seltsam

German Red Cross Blood Service NSTOB Institute Springe

Eldagsener Str. 38, 31832 Springe, Germany Tel. + 495041 772-455, Fax -184

axel.seltsam@bsd-nstob.de 


\section{Introduction}

Improvements in donor screening, good manufacturing practices and viral marker testing have significantly reduced the incidence of transfusion-transmitted infections. However, the blood supply remains under threat from known pathogens which are not assayed in conventional blood screening protocols, from low-titer viruses that escape detection during the window phase of infection, and from novel emerging transfusiontransmissible diseases [1]. A number of different techniques reducing the biological activities of pathogens in blood products have been developed. Current methods use photosensitizers or photoreagents such as methlyene blue, amotosalen or riboflavin followed by irradiation with visible or ultraviolet (UV) light [2]. However, photochemicals or their photoproducts may raise the risk of adverse effects such as immune reactions or toxicity. Even after passing through phase III trials, toxicity might not be revealed until large-scale exposure is seen [3].

Recently, a new method for pathogen reduction in blood units was introduced which is solely based on UVC without the use of any photoactive substance [4-6]. This technology, called THERAFLEX UV-Platelets system, was developed by the Research Foundation of the German Red Cross Blood Services (Forschungsgemeinschaft der DRK-Blutspendedienste e.V.) in cooperation with MacoPharma International $\mathrm{GmbH}$ to be used for the inactivation of pathogens and leukocytes in human platelet concentrates. Beside the INTERCEPT (Cerus Corporation, Concord, CA, USA) and the MIRASOL (CaridianBCT Biotechnologies, Lakewood, CO, USA) systems, UVC treatment is the third technology for pathogen reduction of blood units. This review aims to summarize the current status of development of the UVC system. The principle and the mechanism, the toxicological profile and the pathogen inactivation capacity of this technology will be addressed.

\section{Principle and Mechanism of the Technology}

\section{Active Principle}

It has long been known that UVC is virucidal and microbiocidal $[7,8]$. A long well established method of UVC irradiation of liquids is used for the treatment of drinking water and waste water. These systems are based on the simple concept of placing an UV lamp centrally in a tube and guiding the liquid to be irradiated past this lamp. However, this method is only effective if the liquid is clear or the irradiation dose can be adjusted. UVC has also been employed to sterilize plasma and plasma derivates [9-11]. It is, however, strongly quenched in turbid or protein-containing solutions. To overcome this problem, blood components must be passed through special devices (e.g. rotating irradiation chambers) to realize homogeneous irradiation by UVC. This is not feasible with single blood units under routine production conditions. A higher radiation dose or, more correctly, a higher intensity would be necessary to increase the penetration depth of the UVC light; however, this would cause damage of the proteins and cells in the blood components.

The active principle used in the THERAFLEX UV-Platelets procedure overcomes this quenching problem by combining UVC irradiation with a strong agitation of the blood bags $[4,6]$. Agitation leads to a mixing in the blood bag so that the particles comprising the fluid are transported through the thin photoreactive layer proximate to the surface of the fluid. It is essential for the efficiency of the THERAFLEX UV-Platelets procedure that the blood bags are loosely placed during agitation. In contrast to fixation of blood bags between two quartz plates, the loose placement of the bag allows for an increased mixing rate and wave movement of the bags during agitation. The wave movement causes the formation of areas of layers within the blood unit that become thin enough to be UVC permeable (fig. 1A). Both effects, vigorous and constant mixing and formation of thin layers, may ensure that the entire volume of the blood unit is sufficiently penetrated by UVC light. Experimental data showed that UVC-mediated inactivation of pathogens in unfixed blood bags was agitation speed-dependent and had its maximal efficacy at 100 rotations per minute (rpm) or higher (fig. 1B).

These data suggest that the biological effect of UVC on pathogens inside a blood bag is not simply based on the nominal UVC dose applied but strongly depends on the specific exposure conditions such as the placement, geometry and agitation speed of the treated blood bag. Other parameters such as the cell concentration and the protein content of the irradiated fluid have a great influence on pathogen inactivation efficiency as they critically determine the UVC transparency of the solution to be treated [12]. Thus, only standardized and optimized conditions as realized with the THERAFLEX UV-Platelets procedure and equipment guarantee efficient and reproducible results (table 1 ).

\section{Mechanism of Action}

Short-wave UVC light (wavelength range 200-280 nm) inactivates pathogens mainly by its direct interaction with nucleic acids. This results predominantly in formation of cyclobutane pyrimidine and pyrimidine pyrimidone dimers, which block the elongation of nucleic acid transcripts (fig. 2) [13, 14]. Most of the photoproducts are produced between adjacent pyrimidines. In addition, lesions are generated involving bases located on different DNA strands. Exposure of cells to UVC triggers a global response, which can either counteract the deleterious effects by enabling DNA repair or lead to apoptosis $[15,16]$. If the number of hits at viral, bacterial or cellular DNA or RNA exceeds the repair capacity, cells will die or host cells will be unable to allow replication of the respective virus. The problem of treating blood units with UVC is that cells and proteins or other active substances can also be damaged by the ray treatment. There is, however, physically a dose range in which pathogens can be killed without the biologically active 
A.

Fig. 1. Impact of agitation and bag placement on UVCmediated pathogen inactivation. A Schematic representation of the impact of the experimental setup on UVC pathogen inactivation potential. In contrast to fixed and/or non-agitated platelet concentrates, agitation of loosely placed platelet concentrate bags leads to the formation of areas with thin layers and to effective mixing, thus providing sufficient penetration of UVC light. B Inactivation of S. epidermidis by UVC light. Inactivation kinetics depend on bag placement and agitation speed. $\bullet$ No bacteria detectable by colonyforming assay. *Significant differences to controls were detected at a $p$ value of less than 0.05 (paired t-test).

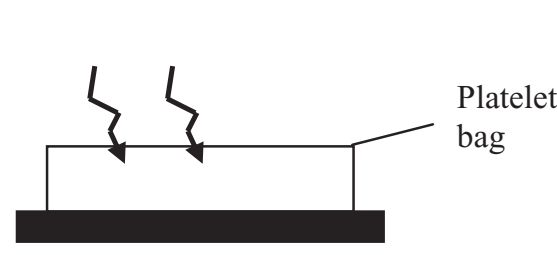

no agitation or agitation of a fixed bag

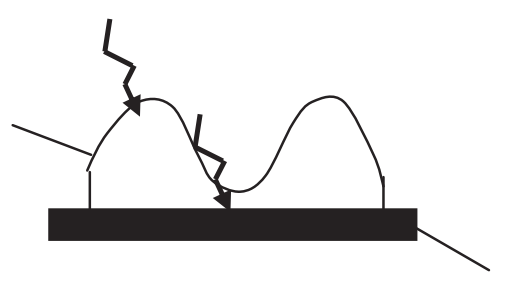

agitation without fixation
Quartz plate

B.

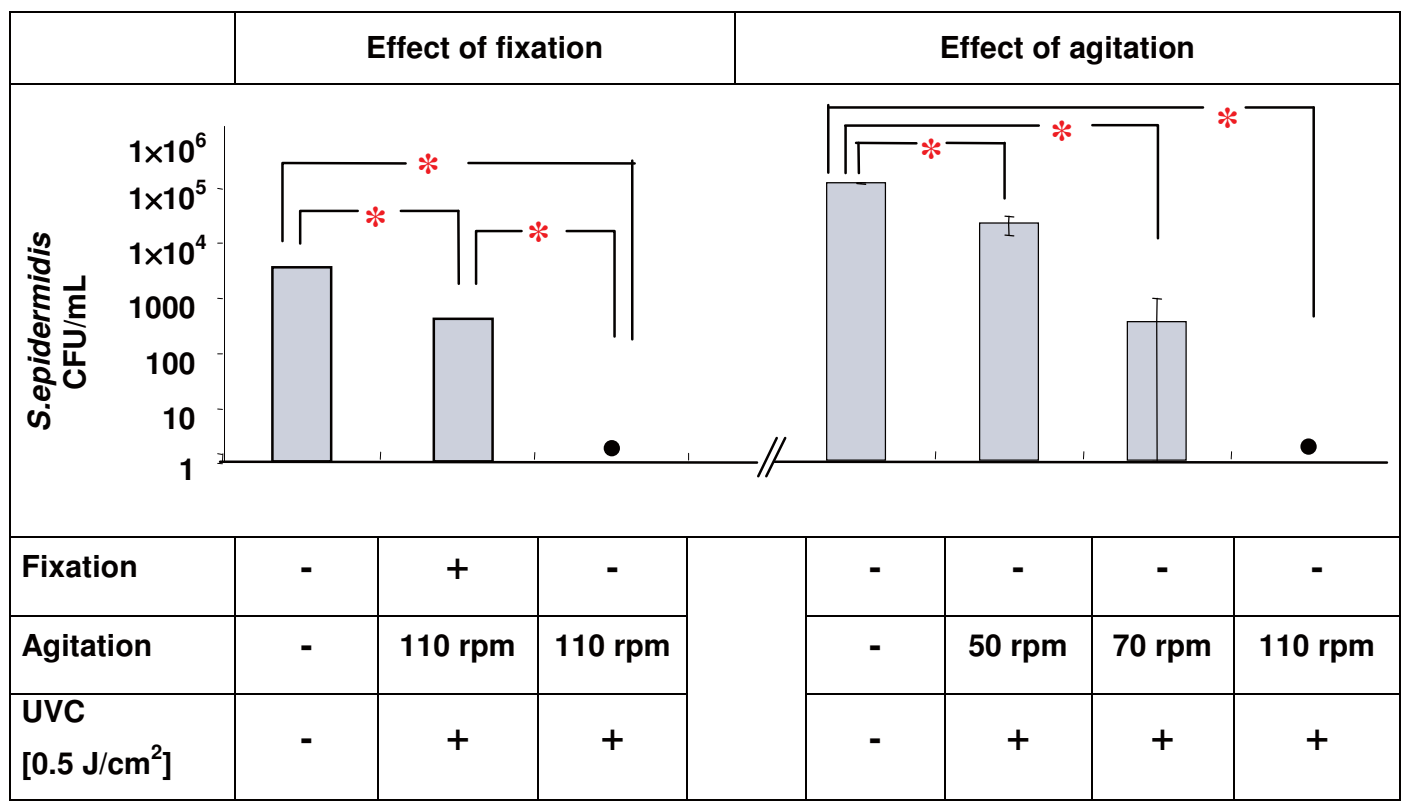

Table 1. Specifications of the THERAFLEX UV-Platelets procedure

\begin{tabular}{ll}
\hline Parameters & Specification \\
\hline Volume of the platelet concentrate & $350 \mathrm{ml}(325-375 \mathrm{ml})$ \\
Platelet concentration & $0.8-1.2 \times 10^{9} / \mathrm{ml}$ \\
Plasma content & $35 \pm 5 \%$ \\
Ratio plasma : SSP+ & $30: 70$ to $40: 60$ \\
UVC dose & $0.2 \mathrm{~J} / \mathrm{cm}^{2}$ \\
\hline
\end{tabular}

components being damaged. As illustrated in figure 3, the damage to pathogens and to proteins depends on the wavelength of UV radiation. At a wavelength of $254 \mathrm{~nm}$, the viruses, bacteria and parasites are damaged more severely than the proteins. The THERAFLEX UV-Platelets procedure exploits these differences to selectively inactivate pathogens.

\section{THERAFLEX UV-Platelets Procedure}

Although the proof of principle of UVC treatment of blood units at a clinical scale has been provided for plasma as well as for platelet concentrates $[4,6]$, only the system for pathogen reduction of platelets has so far been systematically evaluated in preclinical and clinical investigations $[17,18]$. The THERAFLEX UV-Platelets process is a simple three-step procedure in which whole blood-derived or apheresis platelets suspended in plasma with additive solution $\mathrm{SSP}^{+}$(MacoPharma, Tourcoing, France; reference or identical with PAS-IIIM) are first transferred into a UVC-permeable $19 \times$ $38 \mathrm{~cm}$ illumination bag. Then, treatment of platelets with UVC is performed $30 \mathrm{~min}$ to $24 \mathrm{~h}$ after preparation with a UV irradiation device (Macotronic; MacoPharma), whereby illumination of the platelet concentrates is from both sides and the bags are loosely placed on a quartz plate and agitated at $110 \mathrm{rpm}$ with a built-in orbital agitator. The irradiation bag is fixed at its edges by two holders in order to avoid movement of the bag out of the irradiation area while still allowing free movement of the bag walls and the solution inside the bag. An irradiation time of less than $1 \mathrm{~min}$ (usually 20-30 s) is equivalent to the desired biologically active UVC dose. The nominal UVC dose applied to the blood bag depends on the UVC per- 


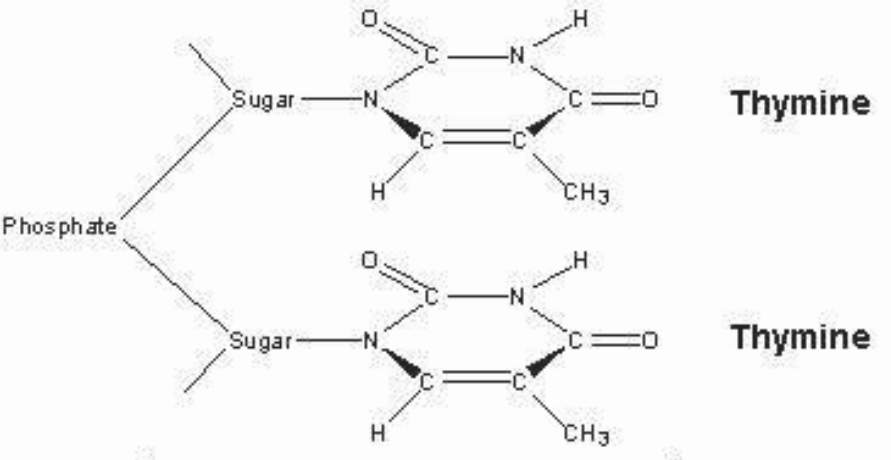

Fig. 2. Mechanism of action of UVC light. The pathogen inactivation by UVC is predominantly based on UV absorption by nucleic acids (DNA and RNA). That in turn causes the formation of cyclobutane pyrimidine and pyrimidine pyrimidone dimers, which block the elongation of nucleic acid transcripts. Most of the dimers are formed between adjacent pyrimidines.

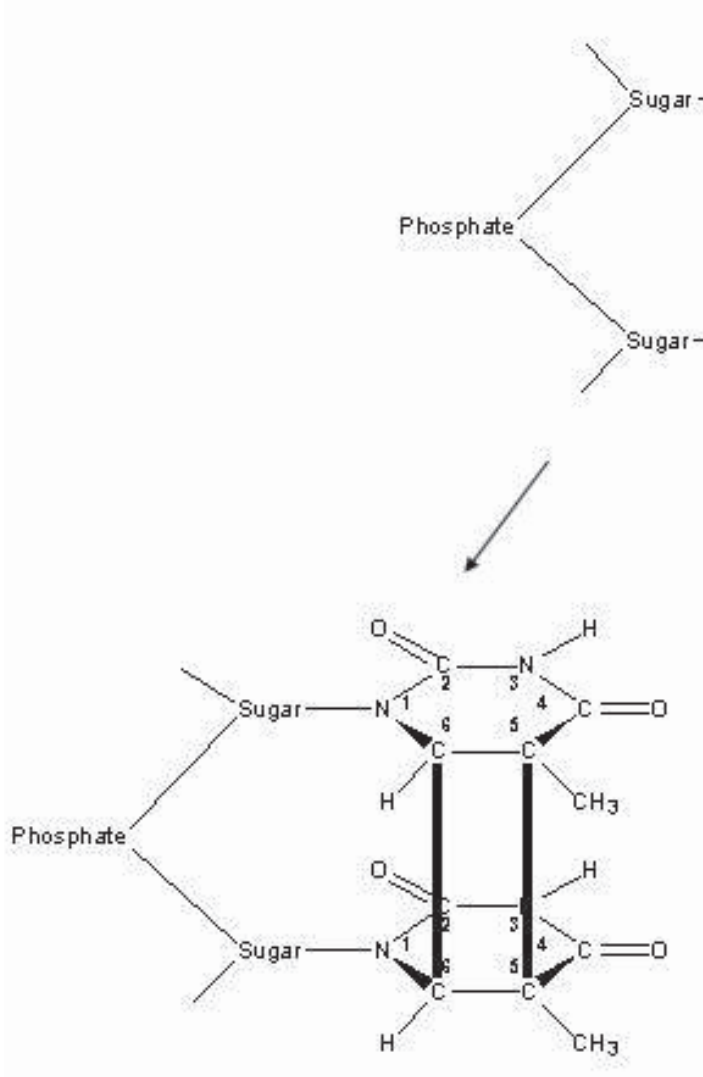

Cyclobutane pyrimidine dimer (CPD)

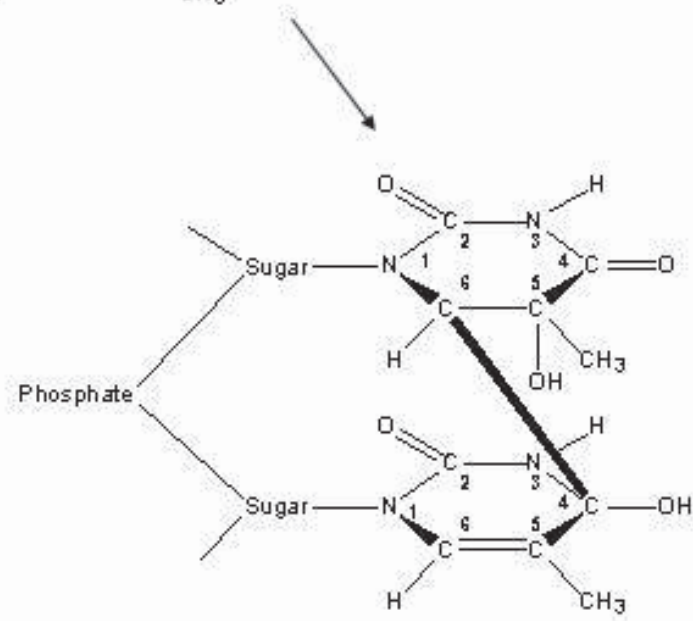

Pyrimidine $6-4$ pyrimidone dimer meability of the plastic material of the illumination bag and is set to $0.2 \mathrm{~J} / \mathrm{cm}^{2}$ in the latest version of the system. To avoid any handling problems that may occur in blood banks and clinics due to the larger size of the irradiation bag, after illumination the platelets are transferred into a storage container and are ready for transfusion with no further processing. The THERAFLEX UV-Platelets procedure and its current specifications are shown in figure 4 and table 1 , respectively.

\section{Procedure for UVC-Irradiated Plasma}

The procedure for UVC irradiation of plasma units has not been fully validated so far. Conditions similar to those used in the THERAFLEX-UV-Platelets system were applied in the preliminary experiments [5]. In vitro data suggest that a UVC dose of $1 \mathrm{~J} / \mathrm{cm}^{2}$ might be appropriate to effectively inactivate pathogens and to obtain a sufficient quality of the coagulation factors.

\section{Studies and Current Knowledge about Toxicity}

\section{Tolerability}

Current clinically approved methods of pathogen reduction in platelet concentrates depend on the addition of photoactive reagents such as amotosalen, a psoralen compound [19], or riboflavin (vitamin B2) followed by UV irradiation [20]. Photochemicals or their photoproducts may raise the risk of adverse effects such as immune reactions, toxicity or even carcinogenicity. Although these adverse effects are estimated to be rather low [21, 22], it has to be taken into account that studies on pharmacokinetics and side effects for all possible minor photoproducts are difficult to perform. In addition, such studies are limited in assessing the safety margin of a chemical substance that is bound to or incorporated by cells when transfused into a patient. Moreover, only long-term studies will be able to determine the risk, particularly of carcinogenesis, of these photoproducts. In contrast, a pathogen reduction procedure without the need of addition and/or removal of any photoactive reagent would exclude photoreagent-related adverse events. UVC irradiation works without the addition of a photoactive substance or additional new impurities so that conventional approaches to toxicity testing as established for pharmaceuticals are not appropriate for UVC-irradiated human blood units using the THERAFLEX UV-Platelets system.

Although the wavelength of $254 \mathrm{~nm}$ used for treatment of blood units is outside the absorption maximum of proteins, UVC light may induce alterations of platelet and plasma proteins. Therefore, preclinical investigations performed with UVC-irradiated platelet concentrates focused on the main safety-relevant end points tolerability and immunogenicity in 
Fig. 3. Schematic drawing of the degree of damage to pathogens (viruses, bacteria, parasites), leukocytes and proteins by UV irradiation with different wavelengths. The wavelength ranges of UVB and UVC as well as the specific wavelength of $254 \mathrm{~nm}$ used in the Theraflex procedure for pathogen reduction in platelet and plasma units are indicated.
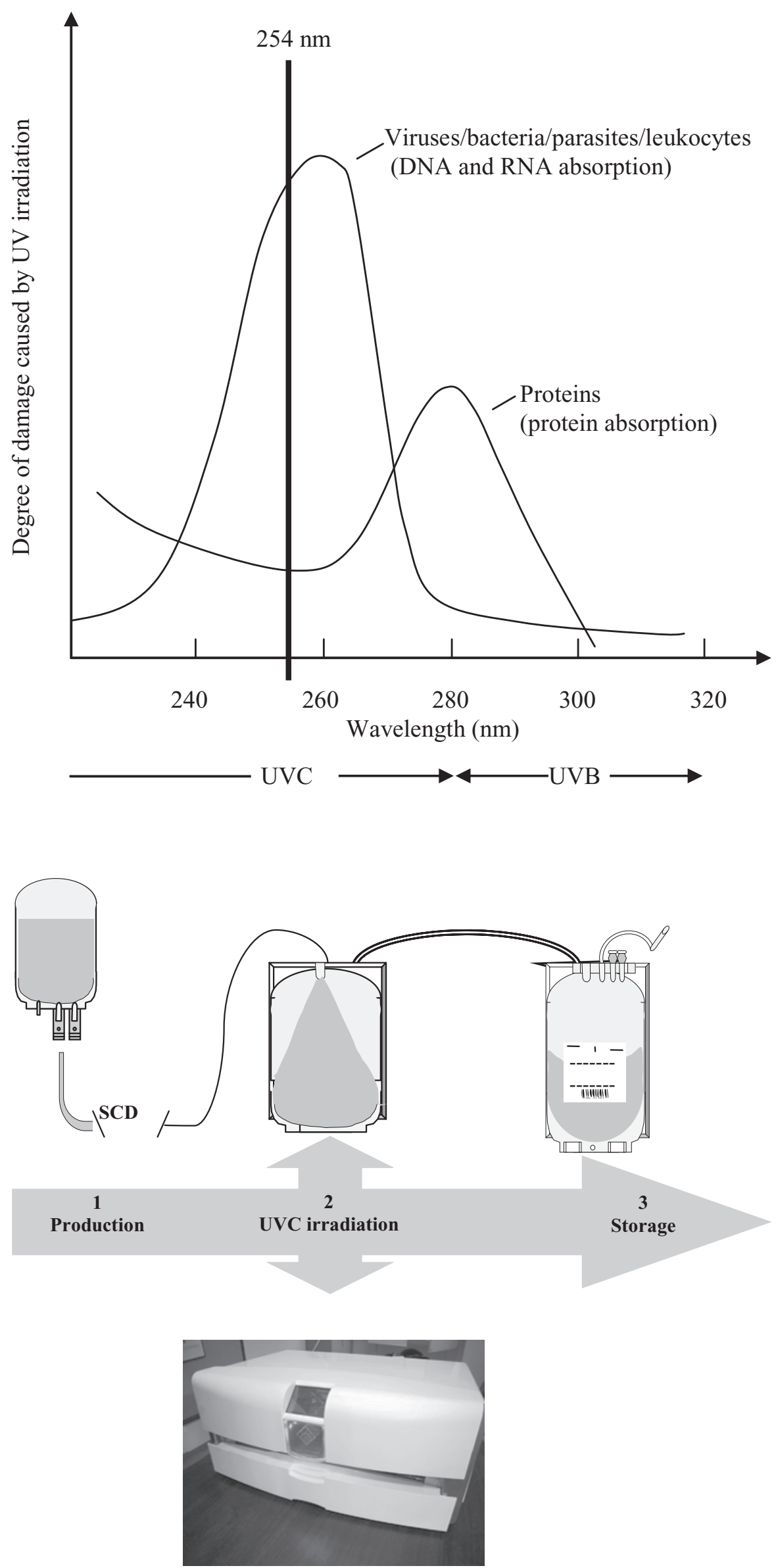

Fig. 4. THERAFLEX UV-Platelets procedure. The THERAFLEX system consists of a UVC illumination device (Macotronic; MacoPharma) and an integral disposable set. The disposable set comprises a plastic illumination bag and a storage bag and provides a single-use, closed, integrated system for pathogen reduction of a platelet unit. The processing steps are described under the section 'Principle and Mechanism of the Technology'. $\mathrm{SCD}=$ sterile connection device. 
Table 2. Quality

control data for untreated control platelet concentrates (PCs) and UVCtreated PCs

\begin{tabular}{|c|c|c|c|c|c|c|}
\hline \multirow[t]{3}{*}{ Parameter } & \multicolumn{6}{|c|}{ Days after UVC irradiation } \\
\hline & \multicolumn{2}{|l|}{ Day 1} & \multicolumn{2}{|l|}{ Day 4} & \multicolumn{2}{|l|}{ Day 6} \\
\hline & control PC & PC-UVC & control PC & PC-UVC & control PC & PC-UVC \\
\hline PLT concentration $\times 10^{9} / \mathrm{ml}$ & $1.19 \pm 0.07$ & $1.15 \pm 0.04$ & $1.15 \pm 0.03$ & $1.13 \pm 0.04$ & $1.13 \pm 0.04$ & $1.11 \pm 0.05$ \\
\hline Swirling & $\mathrm{OK}$ & $\mathrm{OK}$ & $\mathrm{OK}$ & $\mathrm{OK}$ & $\mathrm{OK}$ & $\mathrm{OK}$ \\
\hline $\mathrm{pH}$ & $7.17 \pm 0.03$ & $7.15 \pm 0.05$ & $7.34 \pm 0.07$ & $7.31 \pm 0.08$ & $7.34 \pm 0.06$ & $7.21 \pm 0.04$ \\
\hline Glucose, $\mathrm{mmol} / \mathrm{l}$ & $5.9 \pm 0.5$ & $5.9 \pm 0.5$ & $4.4 \pm 0.4$ & $4.1 \pm 0.6$ & $3.4 \pm 0.6$ & $2.6 \pm 0.8 \dagger$ \\
\hline Lactate, mmol/1 & $8.5 \pm 1.2$ & $8.5 \pm 1.0$ & $10.8 \pm 0.6$ & $11.6 \pm 1.1$ & $12.6 \pm 0.8$ & $14.1 \pm 1.3$ \\
\hline Hypotonic shock response, \% & $79 \pm 3$ & $68 \pm 8$ & $62 \pm 0$ & $56 \pm 7$ & $57 \pm 3$ & $51 \pm 1$ \\
\hline $\begin{array}{l}\text { Collagen-induced aggregation, } \% \\
10 \mu \mathrm{g} / \mathrm{ml} \text { collagen }\end{array}$ & $93 \pm 4$ & $93 \pm 3$ & $88 \pm 4$ & $89 \pm 6$ & $68 \pm 12$ & $77 \pm 9$ \\
\hline $\begin{array}{l}\text { Collagen-induced aggregation, } \% \\
2 \mu \mathrm{g} / \mathrm{ml} \text { collagen }\end{array}$ & $33 \pm 14$ & $59 \pm 7 \dagger$ & $23 \pm 14$ & $34 \pm 12$ & $7 \pm 2$ & $16 \pm 7$ \\
\hline CD62, \% & $44 \pm 13$ & $49 \pm 3$ & $38 \pm 10$ & $44 \pm 2$ & $47 \pm 4$ & $53 \pm 4 \dagger$ \\
\hline Annexin V, \% & $4 \pm 1$ & $3 \pm 1$ & $6 \pm 2$ & $6 \pm 2$ & $7 \pm 2$ & $9 \pm 2$ \\
\hline PAC-1 binding, Geo mean & $571 \pm 127$ & $727 \pm 169 \dagger$ & $412 \pm 115$ & $488 \pm 128 \dagger$ & $530 \pm 193$ & $610 \pm 220$ \\
\hline
\end{tabular}

Table 3. Irradiation conditions described by Verhaar et al. [40] completely differ from those used by the THERAFLEX UVPlatelets procedure

\begin{tabular}{|c|c|c|}
\hline & Verhaar et al.[40] & THERAFLEX \\
\hline Agitation [r.p.m] & 50 & 110 \\
\hline Vessel & $\begin{array}{l}5 \mathrm{ml} \text { in open petri dish } \\
(84 \mathrm{~mm} \text { in diameter })\end{array}$ & $\begin{array}{l}350 \pm 25 \mathrm{ml} \text { in a blood bag } \\
\text { (ethylene vinyl acetate) }\end{array}$ \\
\hline \multicolumn{3}{|l|}{ UVC treatment } \\
\hline Irradiation & from one side & from two sides \\
\hline Dose, $\mathrm{J} / \mathrm{cm}^{2}$ & 0 to 0.15 & 0.2 \\
\hline Intensity, $\mathrm{mW} / \mathrm{cm}^{2}$ & 0.5 & 7 to 8 \\
\hline Irradiation time, $\mathrm{s}$ & 300 & $20-30$ \\
\hline Platelet concentration, cells $/ \mathrm{ml}$ & $5 \times 10^{7}$ & $1 \times 10^{9}$ \\
\hline Plasma content, \% & not clearly indicated, in most cases 0 & $\sim 35$ \\
\hline
\end{tabular}

recipients. A Beagle animal model suitable to predict human response to platelet transfusion was used for the safety pharmacology investigation [23, 24]. Like in the human system, in vitro changes in the metabolic activity and in the platelet proteome occurred after UVC treatment of canine platelet concentrates. However, physical and laboratory investigations did not reveal any signs of local or systemic intolerance in the animals after multiple transfusions of UVC-irradiated canine platelet concentrates [17]. There were no obvious signs of activation of the immune system in the recipient dogs like increase in the number of white blood cells and changes in the lymphocytes subset or swelling of the lymph nodes.

\section{In vitro Quality}

The in vitro quality of plasma proteins and platelets is moderately influenced by UVC treatment. At $1 \mathrm{~J} / \mathrm{cm}^{2} \mathrm{UVC}$ the activities of the clotting factors tested in general were reduced by approximately $10-20 \%$ compared to untreated plasma. More sensitive was clotting factor XI whose activity was lowered by approximately $23 \%$. No further reductions were determined after storage of UVC-treated fresh plasma for
3 months at $-30{ }^{\circ} \mathrm{C}$ or less [5]. While the UVC treatment of plasma units is still under development, the treatment-associated losses of factor activities seem to be similar to those found for more established pathogen inactivation procedures already in use for fresh plasma [25-28].

UVC-treated platelets are characterized by a slightly higher metabolic activity (glucose consumption and lactate accumulation) compared to untreated controls. In addition, increased values for parameters such as CD62 expression, Annexin $\mathrm{V}$ binding and PAC-1 binding indicate a moderate activation of UVC-treated platelets. The most UVC-sensitive in vitro parameter was identified to be the hypotonic shock reaction (HSR) showing a decrease of $20-30 \%$ immediately after UVC irradiation. However, HSR recovers partly during storage of UVC-treated platelets. Thus, in vitro parameters suggest that UVC treatment only moderately influences the functionality of the platelets. Table 2 gives an overview of the quality control data of buffy coat-derived platelet concentrates during storage until day 6 after irradiation.

In vitro quality data of UVC-irradiated platelets are comparable with the quality reported for other pathogen-inac- 
Fig. 5. UVC lightinduced reduction of disulfide bonds on the platelet surface. A The amount of free thiol groups on the platelet surface was measured by the help of maleimide which has a high binding affinity to free thiol groups. Platelets were either left untreated, irradiated with increasing doses of UVC light or treated with dithiothreitol (DTT) as positive control and then incubated with maleimide coupled to the fluorescent dye Alexa633 to label free thiol groups. Binding of the probe was assessed by flow cytometry. Data represent the mean of 4 experiments. B To investigate the effect on $\alpha \operatorname{IIb} \beta 3$ specifically, platelets were incubated with BMCC to biotinylate free thiol groups after the various treatments. Biotinylated proteins were then precipitated with streptavidin agarose beads. The graph depicts the binding of the $\beta 3$ antibody to the immunoblots of the precipitates as quantified on an imaging system and calculated as percentage of the results of the positive control set as $100 \%$. Data represent the mean of 4 experiments. Arrows indicate the dose of 0.2 $\mathrm{J} / \mathrm{cm}^{2}$ as used in the THERAFLEX UVPlatelets system.

*Significant differences between negative controls and irradiated samples were detected at a p value of less than 0.05 (paired t-test).

$\mathbf{A}$

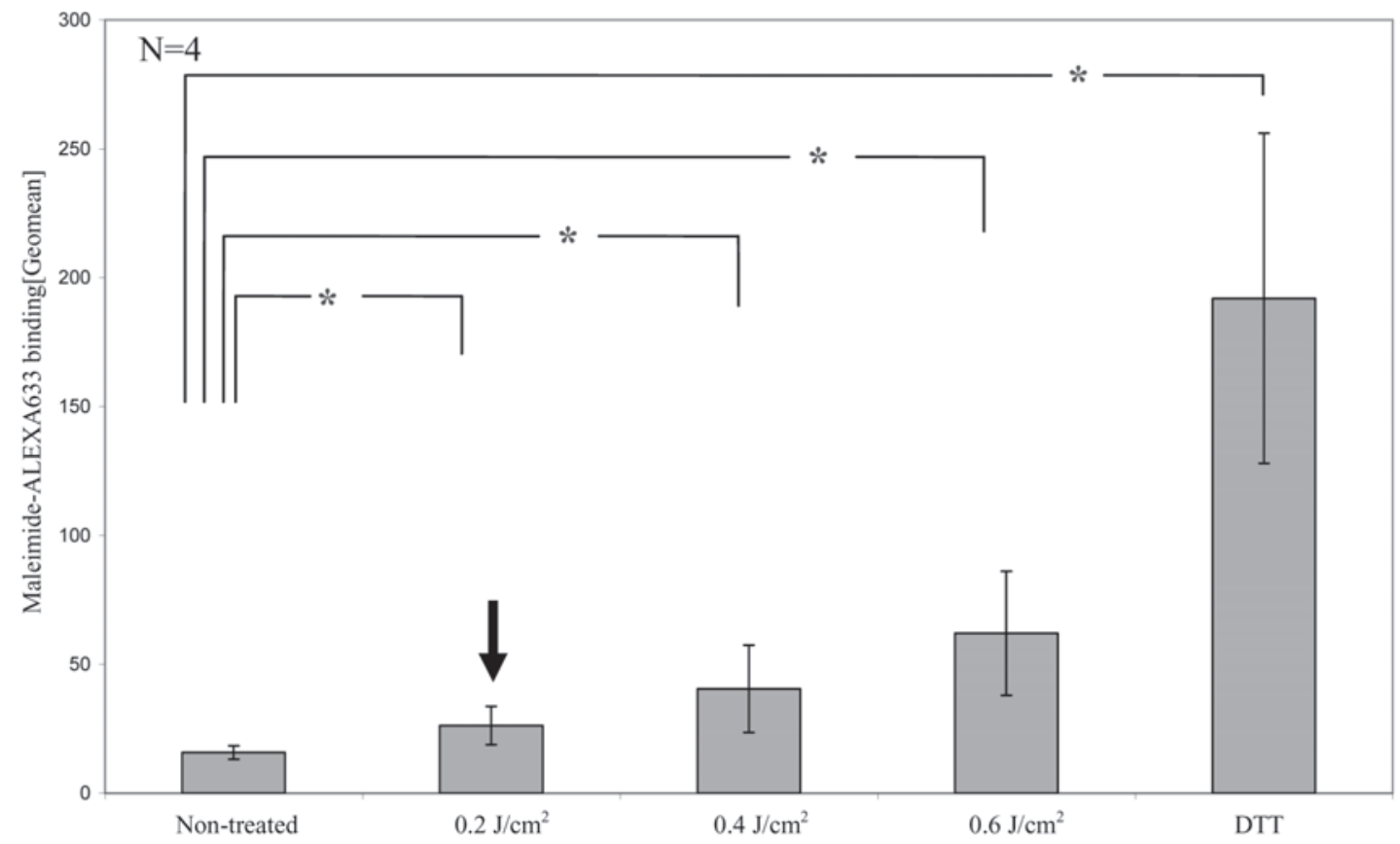

B

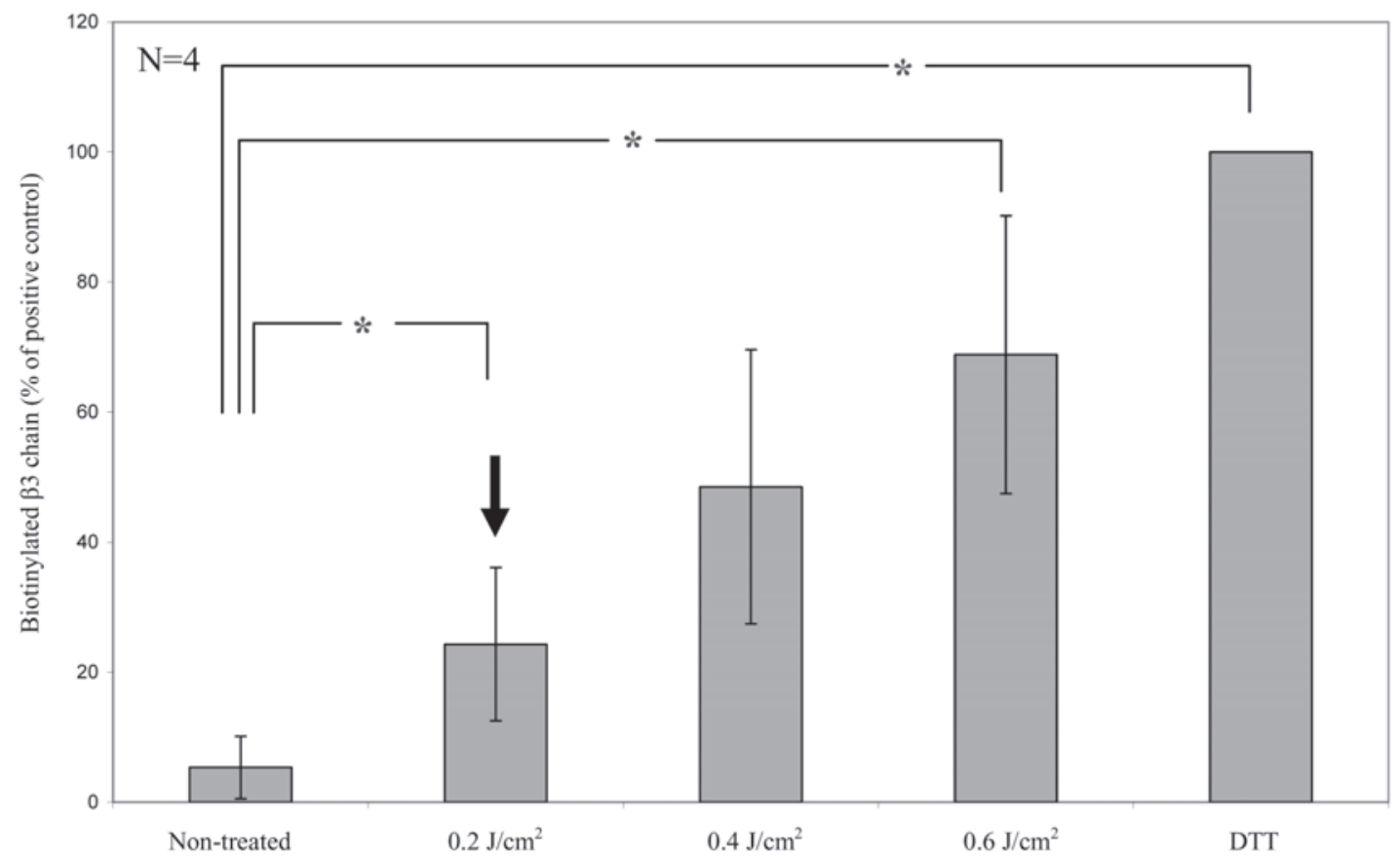

tivated products [29-33]. The relationship between platelet activation in platelet concentrates during storage and platelet function after transfusion and the effect with regard to posttransfusion recovery and survival in recipients is controversial [34-36]. Results on the correlation of other parameters like
HSR or lactate with in vivo functionality of platelets are variable [35, 37-39]. Thus, clinical studies will be necessary to determine the functionality and clinical efficacy of UVCtreated platelets. Preliminary results of a radiolabeling study in healthy donors suggest a reduction in recovery and survival 
of autologous UVC-treated platelets, which is in the same range as has been reported for INTERCEPT and MIRASOL platelets [18].

\section{Proteome}

UVC-induced protein alterations in platelets may be expected for membrane as well as for cytoplasmatic proteins. In a recent biochemical study by Verhaar et al. [40], it was reported that UVC irradiation exerts a direct effect on $\alpha \operatorname{IIb} \beta 3$ (and other integrins) by modifying extracellular disulfide bonds regulating integrin conformation. This direct activation of platelet $\alpha \operatorname{IIb} \beta 3$, the fibrinogen receptor, may result in aggregation of stored platelets and influence the hemostatic function of the platelets. It was hypothesized that UVC irradiation gives platelets a 'sunburn' which may limit its application for pathogen inactivation of blood products. Indeed, disruption of disulfide bonds of $\alpha \mathrm{IIb} \beta 3$ by UVC may be responsible for the increased aggregability and PAC-1 binding detectable in UVC-treated platelets. However, the conditions in the study by Verhaar et al. [40], including plasma content, platelet concentration, intensity and time for UVC delivery, type of irradiation vessel and agitation, were completely different from those used in the THERAFLEX UV-Platelets irradiation procedure (table 3 ). As already mentioned above, the treatment conditions have significant influence on the biological effects of UVC and, thus, on the quality of the product. Although the difference in parameters between the UVC irradiation procedure by Verhaar et al. [40] and the THERAFLEX UV-Platelets system makes it difficult to compare the effective doses, pathogen inactivation data previously published by the same Dutch group strongly suggest that the UVC dose used in the biochemical study was significantly higher than that used in the THERAFLEX UV-Platelets system [12]. Remarkably, for analysis of the disulfide bonds Verhaar et al. [40] washed the platelets before UVC irradiation to remove the plasma although in their previous study [12] they had identified a plasma content of at least $10 \%$ to be critical for their system to achieve good pathogen inactivation in combination with good quality. Thus, one would expect that the Theraflex UV procedure using a lower biologically effective UVC dose activates only a minor part of all the $\alpha \operatorname{IIb} \beta 3$ complexes on the platelet surface.

To test this, we applied the same biological methods as Verhaar et al. [40] to platelets treated with the THERAFLEX system. The amount of free thiol groups on the platelet surface was measured by the help of maleimide which has a high binding affinity to free thiol groups. UVC irradiation caused a dose-dependent increase in free thiol groups on the surface of the platelets, as measured by a fluorescent probe coupled to maleimide (fig. 5A). However, the amount of free thiol groups on platelets was only slightly increased at the standard UVC dose of $0.2 \mathrm{~J} / \mathrm{cm}^{2}$ used in the THERAFLEX UV-Platelets procedure. To investigate the effect on $\alpha \operatorname{IIb} \beta 3$ specifically, free thiol groups were labeled with maleimide-coupled biotin after the various treatments, and biotinylated proteins were then precipitated with streptavidin agarose. As shown in figure $5 \mathrm{~B}$, after UVC irradiation $\alpha \operatorname{IIb} \beta 3$ appeared to be labeled with biotin, indicating an increase in free thiol groups by disruption of disulfide bonds in the fibrinogen receptor. This increase showed similar dose dependence as the increase in total free thiol groups on the membrane surface. Again, there was only a moderate increase of free thiol groups on platelets after irradiation with the UVC dose used in the THERAFLEX UV-Platelets system. The laboratory findings observed in UVC-treated platelets are similar to those detected in platelets after UVB irradiation. In contrast to UVCtreated platelet units which are intended to be irradiated just after preparation and then be stored until transfusion, UVB irradiation of platelets was always performed shortly before transfusion. Van Marwijk and colleagues [41] observed that irradiation of platelets with UVB light results in exposure of fibrinogen binding sites and subsequent platelet aggregation. Another group found an increase in the expression of activation in platelets over time and a reduced post-transfusion recovery of UVB-treated platelets in a dose-dependent manner [42]. However, in the Trial to Reduce Alloimmunization to Platelets (TRAP) [43], in which UVB-irradiated platelets were compared with leukocyte-reduced platelets in their ability to prevent alloimmunization and refractoriness to platelet transfusions, it was found that UVB irradiation did not diminish the clinical efficacy of platelet transfusions. The experiences with UVB-treated platelet concentrates demonstrate that it is not possible to predict the in vivo function of UV-treated platelets from laboratory findings. Therefore, future studies in thrombocytopenic patients will have to show whether UVC-treated platelets are clinically effective in maintaining hemostasis.

For a more comprehensive analysis of the impact of UVC on platelet integrity, a proteome study was conducted on the cytosolic proteins [6]. In a pilot study, platelet samples from untreated and UVC-, UVB- or gamma-irradiated human platelet concentrates were analyzed 1 day after treatment. Cytosolic proteins were labeled with different dyes and separated according to their charges by isoelectric focusing and to their sizes in the same polyacrylamide gels in a two-dimensional differential in gel electrophoresis (2D-DIGE) to quantitatively assess and characterize changes in the cytosolic platelet proteome induced by the different treatments. The quantitative proteomic study indicated that UVC irradiation shows less effect on the platelet proteome than UVB irradiation and gamma irradiation. Analysis revealed a common set of 92 (out of 793) protein spots affected by all three types of irradiation, whereby specific alterations were most pronounced for gamma irradiation (45 spots), followed by UVB (11 spots) and UVC (only 2 spots). Platelet proteome studies are under way that consider also membrane proteins and are designed to monitor protein alterations in UVC- and gammairradiated platelet concentrates during storage. 
Table 4. Inactivation factors of different bacteria in platelet concentrates after THERAFEX UVPlatelets treatment $(\mathrm{N}=6)$

\begin{tabular}{|c|c|c|c|c|}
\hline Species & Aerobic/ anaerobic & Gram stain & Spore former & Reduction factor (log) \\
\hline Bacillus cereus & aerobic & + & + & $4.3 \pm 0.81$ \\
\hline Clostridium perfringens & anaerobic & + & + & $\geq 4.73$ \\
\hline Escherichia coli & fac. anaerobic & - & - & $\geq 4.01$ \\
\hline Enterobacter cloacae & fac. anaerobic & - & - & $\geq 4.29$ \\
\hline Klebsiella pneumoniae & fac. anaerobic & - & - & $4.8 \pm 0.28$ \\
\hline Pseudomonas aeruginosa & aerobic & - & - & $\geq 4.92$ \\
\hline Propionibacterium acnes & anaerobic & + & - & $4.53 \pm 1.13$ \\
\hline Serratia marcescens & fac. anaerobic & - & - & $\geq 4.99$ \\
\hline Staphylococcus aureus & aerobic & + & - & $\geq 4.78$ \\
\hline Staphylococcus epidermidis & aerobic & + & - & $4.83 \pm 0.51$ \\
\hline
\end{tabular}

\section{Studies and Current Knowledge about Neoantigens}

In addition to the risks described, another type of toxicological effect is the elicitation of an immune response to the UVC-treated platelet product. UVC may induce modification of macromolecules on the platelet surface so as to create a new antigen (neoantigen) that may be detected as foreign by the immune system of the platelet recipient. Similar to the situation in patients alloimmunized against platelet antigens (e.g. HLA, HPA), immune response to UVC-induced neoantigens could result in the formation of antibodies that can bind to the altered platelets and cause them to be cleared from the circulation. Until now, such an immune response has not been reported for MIRASOL or INTERCEPT platelets, for which UV-induced alterations may also be expected. Accordingly, in an animal study we could not detect UVCinduced antibodies against plasma or platelet proteins even after repetitive transfusions of UVC-treated platelets, suggesting that potential alterations in UVC-treated platelets are not highly immunogenic [17]. Clinical studies with pathogenreduced red blood cells showed that the use of chemical components can result in the formation of antibodies to chemicaldependent neoantigens. Phase III trials in which PEN110, a low molecular weight, cationic ethyleneimide derivative, was used for pathogen reduction of red blood cells, were suspended after patients with an antibody response to PEN110treated red blood cells had been identified [44]. A similar immunologic problem has been observed with red blood cells treated with the alkylator S-303 [45]. Modification in the S-303 process could reduce but not eliminate this problem [46]. These data suggest that the use of chemical compounds increases the risk for antibody-mediated immune reactions against pathogen-reduced blood cells. The THERAFLEX UV-Platelets procedure, however, has the advantage that it does not need any ingredients to develop its full efficiency. Nevertheless, it will be an important issue in future clinical studies to determine the potential immunogenicity of UVCtreated platelets.

\section{Efficiency of Pathogen Reduction}

\section{Bacteria}

Investigations on bacteria inactivation in platelet concentrates by UVC included a set of bacteria species with different properties, e.g. Gram-positive and Gram-negative species, aerobes and anaerobes, and spore-forming species. Furthermore, species were chosen that had been associated with transfusiontransmitted bacterial infections: Staphylococcus epidermidis, and Klebsiella pneumoniae [47, 48]. The UVC procedure was shown to efficiently inactivate the different strains by at least $4 \log$ steps (table 4) [6]. Taking into account the normally very low bacterial titers in contaminated platelet concentrates at the beginning of storage $(<1 \mathrm{CFU} / \mathrm{ml})$, reduction rates of $>4$ log steps may adequately ensure bacterial inactivation [49].

Depending on the respective national guidelines, platelet concentrates can be stored for 4-7 days after preparation before their transfusion. Because the storage conditions of platelet units (at room temperature under continuous agitation) favor the growth of certain bacteria, residual bacteria might grow up again to high titers during subsequent storage, if the pathogen reduction process was incomplete. As pathogen inactivation is only feasible at the manufacturer's site, a method for routine application should be able to prevent bacterial growth during the storage period. We therefore conducted a study to investigate the sterility of platelet products after UVC treatment and storage for 5-7 days [4]. After spiking with 10-100 CFU/ml, THERAFLEX UV-Platelets treatment was sufficient to sterilize platelet concentrates spiked with a variety of different bacteria strains like Clostridium perfringens, Enterobacter cloacae, Escherichia coli, K. pneumoniae, Propionibacterium acnes, Pseudomonas aeruginosa or S. epidermidis. For the spore forming bacterium Bacillus cereus the procedure seems to have only limited efficiency. Further experiments will have to show whether these results were due to a contamination of the bacteria preparation with spores known to be significantly less susceptible to UVC than vegetative bacteria [50]. Other pathogen reduction procedures like the INTERCEPT system have also been shown to be incapable of ensuring complete inactivation of $B$. cereus 
[51]. Overall, the UVC procedure is a suitable method for efficient and reproducible inactivation of bacterially contaminated platelet concentrates. Given the fact that up to $0.6 \%$ of platelet units from routine production might be bacterially contaminated, the UVC treatment has the potential to significantly contribute to bacterial safety of platelet concentrates [52].

\section{Viruses}

The efficacy of virus reduction in platelet concentrates was demonstrated using different transfusion-relevant viruses as well as model viruses for common transfusion-relevant viruses. Viruses were chosen in accordance with the current guidelines for virus validation studies [53-55]. Viruses like vesicular stomatitis virus, porcine parvovirus (model virus for parvovirus B19), encephalomyocarditis virus (model virus for hepatitis A) and Sindbis virus (model virus for hepatitis C) were inactivated by 4 or more log steps. Pseudorabies virus (model virus for hepatitis B) and West Nile virus were less effectively inactivated with reduction factors of approximately $2-3$ and 3.5-4 $\log$ steps, respectively. With a reduction factor of only $1 \mathrm{log}$, HIV proved to be almost resistant to UVC treatment of platelet concentrates [6]. The diploid nature of the virus genome and the HIV-associated reverse transcriptase, which may be unaffected by UVC, may provide the basis for an effective repair mechanism of the virus [56]. However, for HIV and other agents for which screening is performed, pathogen reduction by UVC could eliminate or (in view of the low UVC sensitivity of HIV) at least further reduce the risk for virus transmission during the pre-nucleic acid testing (NAT) window phase and occult infections [57]. In combination with the routine testing for HIV, HCV and HBV, the THERAFLEX UV-Platelets system will therefore significantly improve the viral safety compared to the standard platelet products.

Due to the quenching effect of protein-containing solutions, a higher UVC dose is needed for treatment of plasma units than for plasma-reduced platelet concentrates to achieve a similar degree of virus reduction. However, since the therapeutic efficacy of plasma units relies on proteins which are less sensitive to UVC than blood cells, a higher effective UVC dose could be applied to plasma units without critical loss of functionality. Data on pathogen inactivation of plasma by UVC are preliminary. The UVC irradiation procedure has not been fully validated so far. However, using similar conditions as in the THERAFLEX-UV-Platelets system, all viruses used, with the exception of HIV type 1, were effectively inactivated at a UVC dose of $1 \mathrm{~J} / \mathrm{cm}^{2}$ [5]. Preliminary data suggest good in vitro quality of plasma proteins after irradiation with a dose of $1 \mathrm{~J} / \mathrm{cm}^{2}$ [5]. Except for HIV, all viruses used for testing were effectively inactivated by $4-6 \log$ steps at this UVC dose.

\section{Parasites}

Protozoa like Plasmodium, Leishmania or Trypanosoma are known to be transmittable by transfusion. Although these pathogens are currently non-endemic in Germany, a certain transfusion risk remains, e.g. by traveling of donors into endemic areas. Currently, the risk of transmission is minimized by exclusion of donors at risk $[58,59]$. Preliminary results suggest that UVC treatment has the potential to inactivate Leishmania infantum and Trypanosoma cruzi [60]. Future studies will have to confirm that UVC treatment of platelet concentrates adds to the safety of blood products with respect to parasites.

\section{Leukocytes}

Residual leukocytes remaining in the product after leukodepletion may give rise to various pathological effects in recipients. Apart from the release of a variety of cytokines into the product, the most serious effect of residual leucocytes is the graftversus-host disease (GvHD) in immunocompromised patients. We performed a series of in vitro experiments to investigate the capacity of UVC to inactivate lymphocytes in platelet concentrates. In mixed lymphocyte cultures, the proliferative responses of alloreactive T cells was inhibited already at low UVC doses. T lymphocytes isolated from UVC-treated platelet concentrates showed clearly reduced proliferative responses after stimulation by the mitogens concanavalin A and phytohemagglutinin. Preliminary investigations showed that the viability of contaminating mononuclear cells (MNCs) was lost throughout the storage period of the platelet concentrates [61]. All these data suggest that residual MNCs in platelet concentrates are effectively inactivated by UVC treatment and that there is a potential for this method to replace gamma-irradiation as state-of-the-art treatment to avoid transfusion-associated GvHD. However, further investigations are currently under way to confirm these results and to quantify the leukocyte inactivation capacity of the THERAFLEX UV-Platelets system.

\section{Current State of Accreditation in Europe}

The irradiation device (Macotronic UV) and the plastic bag system of the THERAFEX UV-Platelets system have been CE-marked in 2009. After successful completion of two phase I safety and tolerability studies, approval by the authorities for a phase III clinical trial is expected.

\section{Acknowledgement}

The authors greatly acknowledge the funding of the 'Forschungsgemeinschaft der DRK- Blutspendedienste e.V.' and of MacoPharma for this project.

\section{Disclosure Statement}

The authors cooperate with MacoPharma in a project to develop the THERAFLEX UV-Platelets system. The authors did not receive any financial support in addition to the project grant and relevant to this manuscript. 


\section{References}

1 Dodd RY: Current risk for transfusion transmitted infections. Curr Opin Hematol 2007;14:671-676.

$\checkmark 2$ Webert KE, Cserti CM, Hannon J, Lin Y, Pavensk K, Pendergrast JM, Blajchman MA: Proceedings of a consensus conference: pathogen inactivationmaking decisions about new technologies. Transfus Med Rev 2008;22:1-34.

3 Teitel JM: Viral safety of haemophilia treatment products. Ann Med 2000;32:485-492.

$\checkmark 4$ Mohr H, Gravemann U, Bayer A, Muller TH Sterilization of platelet concentrates at production scale by irradiation with short-wave ultraviolet light. Transfusion 2009;49:1956-1963.

5 Mohr H, Gravemann U, Müller TH: Inactivation of pathogens in single units of therapeutic fresh plasma by irradiation with ultraviolet light. Transfusion 2009;49:2144-2151.

6 Mohr H, Steil L, Gravemann U, Thiele T, Hammer E, Greinacher A, Müller TH, Volker U: A novel approach to pathogen reduction in platelet concentrates using short-wave ultraviolet light. Transfusion 2009;49:2612-2624.

7 Calkins J, Wheeler JS, Keller CI, Colley E, Hazle JD: Comparative ultraviolet action spectra (254-320 $\mathrm{nm}$ ) of five 'wild-type' eukaryotic microorganisms and Escherichia coli. Radiat Res 1988;114:307-318.

8 Kallenbach NR, Cornelius PA, Negus D, Montgomerie D, Englander S: Inactivation of viruses by ultraviolet light. Curr Stud Hematol Blood Transfus 1989:70-82.

$\checkmark$ Caillet-Fauquet P, Di Giambattista M, Draps ML, Sandras F, Branckaert T, de Launoit Y, Laub R: Continuous-flow UVC irradiation: a new, effective, protein activity-preserving system for inactivating bacteria and viruses, including erythrovirus B19. J Virol Methods 2004;118:131-139.

10 Chin S, Williams B, Gottlieb P, Margolis-Nunno H, Ben-Hur E, Hamman J, Jin R, Dubovi E, Horowitz B: Virucidal short wavelength ultraviolet light treatment of plasma and factor VIII concentrate: protection of proteins by antioxidants. Blood 1995; 86:4331-4336.

11 Hart H, Reid K, Hart W: Inactivation of viruses during ultraviolet light treatment of human intravenous immunoglobulin and albumin. Vox Sang 1993;64:82-88.

12 Terpstra FG, van't Wout AB, Schuitemaker H, van Engelenburg FA, Dekkers DW, Verhaar R, de Korte D, Verhoeven AJ: Potential and limitation of UVC irradiation for the inactivation of pathogens in platelet concentrates. Transfusion 2008;48: 304-313.

13 Cadet J, Sage E, Douki T: Ultraviolet radiationmediated damage to cellular DNA. Mutat Res 2005;571:3-17.

14 Sinha RP, Hader DP: UV-induced DNA damage and repair: a review. Photochem Photobiol Sci 2002;1:225-236.

15 Douki T, Laporte G, Cadet J: Inter-strand photoproducts are produced in high yield within A-DNA exposed to UVC radiation. Nucleic Acids Res 2003;31:3134-3142.

16 Rodrigo G, Roumagnac S, Wold MS, Salles B, Calsou P: DNA replication but not nucleotide excision repair is required for UVC-induced replication protein A phosphorylation in mammalian cells. Mol Cell Biol 2000;20:2696-2705.

17 Pohler P, Lehmann J, Veneruso V, Lambrecht B, Mohr H, Mueller TH, Seltsam A: THERAFLEX UV-platelets: no evidence for intolerance and antibody formation in dogs during a 10-week safety pharmacology study. Transfus Med Hemother 2009;36(suppl 1):47.
18 Bashir S, Thomas S, Cardigan R, Struff WG, Tolksdorf F, Williamson LM: Pathogen inactivation of platelets using UVC light. Transfus Med 2010;20(suppl 1):8.

19 Lin L, Cook DN, Wiesehahn GP, Alfonso R, Behrman B, Cimino GD, Corten L, Damonte PB, Dikeman R, Dupuis K, Fang YM, Hanson CV, Hearst JE, Lin CY, Londe HF, Metchette K, Nerio AT, Pu JT, Reames AA, Rheinschmidt M, Tessman J, Isaacs ST, Wollowitz S, Corash L: Photochemical inactivation of viruses and bacteria in platelet concentrates by use of a novel psoralen and long-wavelength ultraviolet light. Transfusion 1997;37:423-435.

20 Goodrich RP: The use of riboflavin for the inactivation of pathogens in blood products. Vox Sang 2000;78(suppl 2):211-215.

21 Reddy HL, Dayan AD, Cavagnaro J, Gad S, Li J, Goodrich RP: Toxicity testing of a novel riboflavin-based technology for pathogen reduction and white blood cell inactivation. Transfus Med Rev 2008;22:133-153.

22 Ciaravino V, McCullough T, Cimino G, Sullivan T: Preclinical safety profile of plasma prepared using the INTERCEPT Blood System. Vox Sang 2003; 85:171-182.

23 Slichter SJ, Deeg HJ, Kennedy MS: Prevention of platelet alloimmunization in dogs with systemic cyclosporine and by UV-irradiation or cyclosporineloading of donor platelets. Blood 1987;69:414-418.

24 Slichter SJ, Fish D, Abrams VK, Gaur L, Nelso $\mathrm{K}$, Bolgiano D: Evaluation of different methods of leukoreduction of donor platelets to prevent alloimmune platelet refractoriness and induce tolerance in a canine transfusion model. Blood 2005; 105:847-854

25 Singh Y, Sawyer LS, Pinkoski LS, Dupuis KW, Hsu JC, Lin L, Corash L: Photochemical treatment of plasma with amotosalen and long-wavelength ultraviolet light inactivates pathogens while retaining coagulation function. Transfusion 2006;46:1168-1177.

26 Goodrich RP, Edrich RA, Li J, Seghatchian J: The Mirasol $^{\mathrm{TM}}$ PRT system for pathogen reduction of platelets and plasma: an overview of current status and future trends. Transfus Apher Sci 2006;35:5-17.

27 Solheim BG, Seghatchian J: Update on pathogen reduction technology for therapeutic plasma: an overview. Transfus Apher Sci 2006;35:83-90.

28 Garwood M, Cardigan RA, Drummond O, Hornsey VS, Turner CP, Young D, Williamson LM, Prowse CV: The effect of methylene blue photoinactivation and methylene blue removal on the quality of fresh-frozen plasma. Transfusion 2003; 43:1238-1247.

29 van Rhenen DJ, Vermeij J, Mayaudon V, Hind C, Lin L, Corash L: Functional characteristics of S-59 photochemically treated platelet concentrates derived from buffy coats. Vox Sang 2000;79:206-214.

30 Moog R, Frohlich A, Mayaudon V, Lin L: In vitro evaluation of COM.TEC apheresis platelet concentrates using a preparation set and pathogen inactivation over a storage period of five days. J Clin Apher 2004;19:185-191.

31 Ruane PH, Edrich R, Gampp D, Keil SD, Leonard RL, Goodrich RP: Photochemical inactivation of selected viruses and bacteria in platelet concentrates using riboflavin and light. Transfusion 2004; 44:877-885.

32 AuBuchon JP, Herschel L, Roger J, Taylor H, Whitley P, Li J, Edrich R, Goodrich RP: Efficacy of apheresis platelets treated with riboflavin and ultraviolet light for pathogen reduction. Transfusion 2005;45:1335-1341.
3 Apelseth TO, Bruserud O, Wentzel-Larsen T, Bakken AM, Bjorsvik S, Hervig T: In vitro evaluation of metabolic changes and residual platelet responsiveness in photochemical treated and gamma-irradiated single-donor platelet concentrates during long-term storage. Transfusion 2007; 47:653-665.

34 Shanwell A, Diedrich B, Falker C, Jansson B, Sandgren P, Sundkvist L, Svensson L, Vesterinen $\mathrm{M}$, Gulliksson $\mathrm{H}$ : Paired in vitro and in vivo comparison of apheresis platelet concentrates stored in platelet additive solution for 1 versus 7 days. Transfusion 2006;46:973-979.

35 Dijkstra-Tiekstra MJ, Pietersz RN, Huijgens PC: Correlation between the extent of platelet activation in platelet concentrates and in vitro and in vivo parameters. Vox Sang 2004;87:257-263.

36 Berger G, Hartwell DW, Wagner DD: P-Selectin and platelet clearance. Blood 1998;92:4446-4452.

37 Cardigan R, Turner C, Harrison P: Current methods of assessing platelet function: relevance to transfusion medicine. Vox Sang 2005;88:153-163.

38 Goodrich RP, Li J, Pieters H, Crookes R, Roodt J, Heyns Adu P: Correlation of in vitro platelet quality measurements with in vivo platelet viability in human subjects. Vox Sang 2006;90:279-285.

39 Rinder HM, Smith BR: In vitro evaluation of stored platelets: is there hope for predicting posttransfusion platelet survival and function? Transfusion 2003;43:2-6.

40 Verhaar R, Dekkers DW, De Cuyper IM, Ginsberg $\mathrm{MH}$, de Korte D, Verhoeven AJ: UV-C irradiation disrupts platelet surface disulfide bonds and activates the platelet integrin alphaIIbbeta3. Blood 2008;112:4935-4939.

41 van Marwijk Kooy M, Akkerman JW, van Asbeck S, Borghuis L, van Prooijen HC: UVB radiation exposes fibrinogen binding sites on platelets by activating protein kinase $\mathrm{C}$ via reactive oxygen species. Br J Haematol 1993;83:253-258.

42 Grijzenhout MA, Aarts-Riemens MI, Akkerman JW, Nieuwenhuis HK, van Weelden H, van Prooijen HC: Ultraviolet-B irradiation of platelets induces a dose-dependent increase in the expression of platelet activation markers with storage. $\mathrm{Br} \mathrm{J}$ Haematol 1993;83:627-632.

43 The Trial to Reduce Alloimmunization to Platelets Study Group: Leukocyte reduction and ultraviolet $\mathrm{B}$ irradiation of platelets to prevent alloimmunization and refractoriness to platelet transfusions. N Engl J Med 1997;337:1861-1869.

44 Zavizion B, Purmal A, Chapman J, Alford B: Inactivation of mycoplasma species in blood by INACTINE PEN110 process. Transfusion 2004;44:286293.

45 Benjamin RJ, McCullough J, Mintz PD, Snyder E, Spotnitz WD, Rizzo RJ, Wages D, Lin JS, Wood L, Corash L, Conlan MG: Therapeutic efficacy and safety of red blood cells treated with a chemical process (S-303) for pathogen inactivation: a phase III clinical trial in cardiac surgery patients. Transfusion 2005;45:1739-1749.

46 North AK, Henschler R, Geisen C, Garratty G, Arndt PA, Kattamis A, Cohen A, Piga A, Arslan O, Galanello R: Evaluation of naturally occurring antibodies to pathogen inactivated red blood cells. Transfusion 2010;50(suppl):38A.

47 Keller-Stanislawski B, Lohmann A, Gunay S, Heiden M, Funk MB: The German Haemovigilance System - reports of serious adverse transfusion reactions between 1997 and 2007. Transfus Med 2009; 19:340-349. 
48 Brecher ME, Hay SN: Bacterial contamination of blood components. Clin Microbiol Rev 2005;18: 195-204.

49 Murphy WG, Foley M, Doherty C, Tierney G, Kinsella A, Salami A, Cadden E, Coakley P: Screening platelet concentrates for bacterial contamination: low numbers of bacteria and slow growth in contaminated units mandate an alternative approach to product safety. Vox Sang 2008;95:13-19.

50 Setlow P: Resistance of spores of Bacillus species to ultraviolet light. Environ Mol Mutagen 2001;38: 97-104.

51 Knutson F, Alfonso R, Dupuis K, Mayaudon V, Lin L, Corash L, Hogman CF: Photochemical inactivation of bacteria and HIV in buffy-coat-derived platelet concentrates under conditions that preserve in vitro platelet function. Vox Sang 2000;78. 209-216.

52 Walther-Wenke G, Doerner R, Montag T, Greiss O, Hornei B, Knels R, Strobel J, Volkers P, Daubener W: Bacterial contamination of platelet concentrates prepared by different methods: results of standardized sterility testing in Germany. Vox Sang 2006;90:177-182.
53 CPMP: Note for guidance on virus validation studies: the design, contribution and interpretation of studies validating the inactivation and removal of viruses. CPMP/BWP/268/95 1996

54 CPMP: Note for guidance on plasma-derived medicinal products. CPMP/BWP/269/95 rev3 2001

55 Paul-Ehrlich-Institut: Anforderungen an Validierungsstudien zum Nachweis der Virussicherheit von Arzneimitteln aus menschlichem Blut oder Plasma. Bundesanzeiger 1994;84:4742-4744.

56 Henderson EE, Tudor G, Yang JY: Inactivation of the human immunodeficiency virus type 1 (HIV-1) by ultraviolet and X irradiation. Radiat Res 1992; 131:169-176.

57 Goodrich RP, Custer B, Keil S, Busch M: Defining 'adequate' pathogen reduction performance for transfused blood components. Transfusion 2010;50: 1827-1837.

58 Mitteilungen des Arbeitskreises Blut des Bundesministeriums für Gesundheit: Arboprotozoen. Stellungnahmen des Arbeitskreises Blut des Bundesministeriums für Gesundheit. Bundesgesundheitsbl Gesundheitsforsch Gesundheitsschutz 2009; 52:122-146.
59 Mitteilungen des Arbeitskreises Blut des Bundesministeriums für Gesundheit: Malaria. Stellungnahmen des Arbeitskreises Blut des Bundesministeriums für Gesundheit. Bundesgesundheitsbl Gesundheitsforsch Gesundheitsschutz 2008; 51:236-249.

60 Castro E, Girones N, Guerrero N, Barea L, Fresno M: The effectiveness of UVC pathogen inactivation system on reducing the Trypanosoma cruzi and Leishmania infantum burden in platelets. Vox Sang 2008;95:290.

61 Gravemann U, Pohler P, Lambrecht B, Mohr H, Müller TH: Inactivation of peripheral blood mononuclear cells by UVC light using the Theraflex UV-Platelet system. Transfus Med Hemother 2008:35(suppl 1):4. 